\title{
Chemical Composition of the Fatty Oil from Fructus Broussonetiae and Its Effects on Rat Plasma Lipids and Adipose Tissue
}

\author{
Suqiu Pang1,2, Guoquan Wang ${ }^{*}$, Xiaoqin Jin², Aijing Sun ${ }^{1,2}$, Junsheng Lin', Yong Diao1 \\ ${ }^{1}$ School of Biomedical Sciences, Huaqiao University, Quanzhou, China \\ ${ }^{2}$ Department of Pharmacy, Haixia Hospital, Quanzhou, China \\ Email: *1074730795@qq.com
}

Received 30 January 2016; accepted 6 March 2016; published 10 March 2016

Copyright (C) 2016 by authors and Scientific Research Publishing Inc.

This work is licensed under the Creative Commons Attribution International License (CC BY).

http://creativecommons.org/licenses/by/4.0/

(c) (i) Open Access

\begin{abstract}
Context: Broussonetia papyrifera (L.) Vent. (Moraceae), a traditional Chinese medicinal herb, has been extensively applied for many years to treat various diseases. Its fruits (Fructus Broussonetiae) have been commonly used as an important tonic for the treatment of age-related disorders with long history; recent research has proved that it contains $32 \%$ to $35 \%$ fixed oils. The fixed oil is composed mainly of unsaturated fatty acids, including linoleic acid, methyl palmitate, oleic acid and linoleic acid ester. Objective: To investigate the chemistry of the fatty oil from Fructus Broussonetiae (FOFB) and its effects on plasma lipids. Methods: The chemical composition of FOFB was examined and identified by GC-MS. Thirty male Wistar rats fed diet containing FOFB and cholesterol were studied for 28 days. The effect of dietary FOFB on plasma lipids and adipose tissue was tested. Results: Twelve compounds of FOFB were examined and identified, the major components of fatty oil, 8,11-octadecadienoic acid (83.75\%), palmitic acid $(10.22 \%)$, octadecadienoic acid $(2.97 \%)$ and 9-octadecenoic acid (1.69\%) were found. FOFB significantly exhibited the activities of decreasing the rat adipose tissue weight, triacylglycerol, total cholesterol, and low-density lipoprotein cholesterol (LDL-C) concentrations while the rat body weight remained unchanged. Discussion: FOFB contained a large amount of PUFA which had the effect on reducing plasma lipids and adipose.
\end{abstract}

\section{Keywords}

Fructus Broussonetiae, Polyunsaturated Fatty Acids, Plasma Lipids, Adipose Tissue, Rat

\footnotetext{
${ }^{*}$ Corresponding author.
} 


\section{Introduction}

Unsaturated fatty acid (USFA) is a kind of body fat acid, and the most essential body fatty acids are USFA. USFA, according to the different numbers of the double bond, is divided into monounsaturated fatty acid (MUFA) and polyunsaturated fatty acids (PUFA). In the dietary fats, MUFA includes oleic acid, and PUFA includes linoleic acid, linolenic acid, arachidonic acid, etc. Linoleic acid and linolenic acid cannot be synthesized by human body; they must be supplied by the diet. If the dietary unsaturated fatty acid is insufficient, it is easy to cause the blood low-density lipoprotein and LDL-cholesterol increasing, which can cause atherosclerosis and cardiovascular diseases.

Broussonetia papyrifera (L.) Vent. (Moraceae) is a deciduous plant widely distributed all over China. Fruits of the plant are commonly named Fructus Broussonetiae (FB). In traditional Chinese medicine, FB is used to nourish yin and tonify the blood, replenish liver and kidney, improve eyesight and promote urination, and can be used for treating soreness and weakness of waist and knees, fatigue, severe fever and dizziness [1]. And it has been used for impotency and to treat ophthalmic disorders [2] for more than one thousand years. Different extracts of B. papyrifera from a number of laboratories have been shown antifungal [3], antithepatotoxic [4] [5], antioxidant [6], lens aldose reductase inhibitory activities [7], and its extract improves cognitive function and endoplasmic reticulum stress in Alzheimer's disease models [8]. Fatty oil of FB (FOFB) is rich in polyunsaturated fatty acids (PUFA) [9], which plays an important role in reducing long-chain saturated fatty acids level by suppression of fatty acid synthase (FAS) [10]. The FOFB has significant antioxidant effect and can scavenge and inhibit oxygen free radical [11]. Furthermore, it is able to suppress LPS induced NO production in RAW264.7 macrophages [12]. In this study, we investigate the chemical components of the FOFB. We also used rats as a model feeding with FOFB diets to investigate the effects of the FOFB on the concentration of plasma lipids, hepatic lipids and the weight of the adipose tissue.

\section{Materials and Methods}

\subsection{Raw Materials}

B. papyrifera fruits were collected from Quanzhou, Fujian Province, China in autumn, 2011. The specimens were identified by Prof. HUANG BK (Second Military Medical University). Voucher specimens (voucher No. 20110915) were deposited at School of Biomedical Sciences, Huaqiao University of China. The fresh fruits were washed, dried and the grey white membranous persistent calyx and impurities were removed. FB (2.5 kg) was obtained and stored in a vacuum dryer for further use.

\subsection{Chemical Analysis of Fatty Oil}

Samples of FOFB were extruded from FB using an extruder (D-1683, Henan, China) at speeds of 70 - 80 rpm. The obtained orange fatty oil samples were analyzed by Gas chromatography-mass spectrometry (GC-MS) (HP 5890/HP 5973 instrument), which was fitted with capillary glass column DB-wax (30 m $\times 0.25 \mathrm{~mm} \times 0.25 \mu \mathrm{m})$. The column was temperature programmed as follow: $50^{\circ} \mathrm{C}(2 \mathrm{~min}), 50^{\circ} \mathrm{C}-70^{\circ} \mathrm{C}$ at $4{ }^{\circ} \mathrm{C} / \mathrm{min}$ then $70^{\circ} \mathrm{C}-300^{\circ} \mathrm{C}$ at $10^{\circ} \mathrm{C} / \mathrm{min}$ with helium as the carrier gas. Injector temperature was $250^{\circ} \mathrm{C}$. Mass spectra were obtained by scanning from $\mathrm{m} / \mathrm{z} 35$ to 500 with a 0.7 s scan time.

The individual oil components were separated and identified by comparison of their retention indices and mass spectra with the NIST 98 and Wiley Mass Spectral Libraries. The relative amounts of individual components were expressed as percentages of the peak area relative to the total peak area.

\subsection{Animals and Their Treatment}

Experiments in animals were approved by the Laboratory Animal Care Committee of our institution and were conducted in compliance with our institution's ethical guidelines for animal research.

Thirty male Wistar rats (5-week-old) were housed individually in metallic cages in an animal room kept at $25^{\circ} \mathrm{C} \pm 1{ }^{\circ} \mathrm{C}$ and $60 \% \pm 5 \%$ relative humidity with a 12:12-h light-dark cycle (lighting from 8:00 a.m. to 8:00 p.m.). The rats were fed with an adaptation diet for 1 week, and then divided randomly into three groups (each group 10 rats) for designed diets: 1) 10\% lard (control) group; 2) 5\% FOFB group (5\% FOFB + 5\% lard); 3) 10\% FOFB group (10\% FOFB). The recipes of the three experimental diets are shown in Table 2. Fresh diets and 
drinking water were available ad libitum for 28 days. Food intake was measured daily, and body weight was measured at every seventh day. Fatty acid compositions of the three experimental diets were determined by Gas chromatography.

\subsection{Blood and Tissue Sampling}

At the end of the feeding period (4 weeks), the rats were deprived of food for $12 \mathrm{~h}$, and then blood samples (with sodium citrate $0.5 \mathrm{mg} / \mathrm{ml}$ as anticoagulant) were collected from fossa orbitalis under chloraldurat anesthesia. After the blood sampling, the animals were killed immediately by dislocating cervical, the heart, liver and adipose tissue were isolated, weighted and immediately frozen and stored at $-80^{\circ} \mathrm{C}$ until used for analysis. Relative heart (liver, adipose tissue) weight was expressed as heart (liver, adipose tissue) weight (g) $\times 100 /$ final body weight (g).

\subsection{Measurement of the Plasma Lipids and Lipoproteins}

Plasma samples were obtained by centrifugation (1388 g for $10 \mathrm{~min}$ at $10^{\circ} \mathrm{C}$ ). Plasma total cholesterol (CHO) and triacylglycerol (TG) were determined by CHOD-PAP and GPO-PAP methods using CHO and TG testing kits, respectively. High-density lipoprotein (HDL-C) and Low-density lipoprotein (LDL-C) in plasma were separated by ultracentrifugation $\left(194,000 \mathrm{~g}\right.$ for $3 \mathrm{~h}$ at $\left.10^{\circ} \mathrm{C}\right)$, and determined by direct method using HDL-C and LDL-C kits. All kits were purchased from Beijing jiuqiang Bio-Tech Com., China. All biochemical indicators were measured using a conventional automated analyzer (Beckman Au680, USA).

\subsection{Measurement of Liver Cholesterol}

Total cholesterol in the liver was assayed from the total lipids extracted by the Folch method [13].

\subsection{Statistical Analysis}

Each result was given as the mean \pm standard deviations (S.D.). Statistical differences among groups were calculated using one-way ANOVA (SAS Institute, Cary, NC), and group means were considered to be significantly different at $\mathrm{p}<0.05$ as determined by Duncan’s new multiple-range test.

\section{Results and Discussion}

\subsection{Chemical Constituents of Fatty Oil of Fructus Broussonetiae}

GC and MS are powerful tools for chemical analysis, especially when used together. All of the components in a sample can be separated by GC analysis, and at the same time GC analysis provides a representative spectral output. The size of the peak is proportional to the quantity of the corresponding substances in the specimen analyzed. MS identifies substances by electrically charging the specimen molecules, accelerating them through a magnetic field, breaking the molecules into charged fragments and detecting the different charges. MS analysis is highly reliable if the instrument is of sufficient resolution and the technician's interpretation of the results is competent.

The chemical components of FOFB were examined by GC-MS thereby 12 components were identified (Table 1). The main components of fatty oil with concentrations higher than $1.5 \%$ as percentage peak areas were 8,11-octadecadienoic acid (83.75\%), palmitic acid (10.22\%), octadecadienoic acid (2.97\%) and 9-octadecenoic acid (1.69\%), respectively.

\subsection{Effects of FOFB Diets on the Organs and Body Weight}

Fatty acid compositions of the three experimental diets were determined by GC (Table 2). All animals fed with the experimental diets appeared healthy without observable pathological signs or abnormalities during the feeding period. Rats fed with FOFB showed no significant differences in food intaking (g/day/rat), body weight gain and relative organs weights among different diets fed rats. However, epididymal fat pad was significantly decreased $(\mathrm{P}<0.05)$ in both the groups with 5\% and 10\% FOFB; adipose tissue weight and relative adipose tissue weight were significantly diminished $(\mathrm{P}<0.05)$ in $10 \%$ FOFB group (Table 3$)$. 
Table 1. Chemical constituents and contents of oil in FB.

\begin{tabular}{ccccc}
\hline No. & Component & Formula & Molecule weight & Relative content \\
\hline 1 & Tetradecanoic acid & $\mathrm{C}_{14} \mathrm{H}_{28} \mathrm{O}_{2}$ & 228 & 0.2 \\
2 & Palmitic acid & $\mathrm{C}_{16} \mathrm{H}_{32} \mathrm{O}_{2}$ & 256 & 10.22 \\
3 & 8,11-Octadecadienoic acid & $\mathrm{C}_{18} \mathrm{H}_{32} \mathrm{O}_{2}$ & 280 & 83.75 \\
4 & 9 -Octadecenoic acid & $\mathrm{C}_{18} \mathrm{H}_{34} \mathrm{O}_{2}$ & 282 & 1.69 \\
5 & Octadecanoic acid & $\mathrm{C}_{18} \mathrm{H}_{36} \mathrm{O}_{2}$ & 284 & 2.97 \\
6 & 9,12 -octadecadienoic acid & $\mathrm{C}_{18} \mathrm{H}_{32} \mathrm{O}_{2}$ & 280 & 0.37 \\
7 & 11,14 -Eicosadienoic acid & $\mathrm{C}_{20} \mathrm{H}_{36} \mathrm{O}_{2}$ & 308 & 0.3 \\
8 & 11-Eicosenoic acid & $\mathrm{C}_{20} \mathrm{H}_{38} \mathrm{O}_{2}$ & 310 & 0.21 \\
9 & Eicosenoic acid & $\mathrm{C}_{20} \mathrm{H}_{40} \mathrm{O}_{2}$ & 312 & 0.1 \\
10 & Docosanoic acid & $\mathrm{C}_{22} \mathrm{H}_{44} \mathrm{O}_{2}$ & 340 & 0.08 \\
11 & $\delta$-Tocopherol & $\mathrm{C}_{27} \mathrm{H}_{46} \mathrm{O}_{2}$ & 402 & 0.08 \\
\hline
\end{tabular}

Table 2. Fatty acid composition of dietary fats (\%).

\begin{tabular}{cccc}
\hline Fatty acid (carbons (unsaturated carbons)) & Control & $5 \%$ FOFB & $10 \%$ FOFB \\
\hline $14(0)$ & 2.21 & 1.15 & 0.20 \\
$16(0)$ & 25.24 & 17.81 & 10.22 \\
$16(1)$ & 4.35 & 2.14 & trace \\
$18(0)$ & 12.99 & 8.04 & 2.97 \\
$18(1)$ & 41.48 & 21.58 & 84.05 \\
$18(2)$ & 13.26 & 48.53 & 13.39 \\
SFA & 40.44 & 27.00 & 84.05 \\
PUFA & 13.26 & 48.53 & 1.69 \\
MUFA & 45.83 & 23.72 & 6.28 \\
P/S & 0.33 & 1.80 & 6.40 \\
P + M)/S & 1.46 & 2.68 & 49.73 \\
P/M & 0.29 & 2.05 & 0.13 \\
M/S & 1.13 & 0.88 & \\
\hline
\end{tabular}

SFA: saturated fatty acid. PUFA: polyunsaturated fatty acid. MUFA: monounsaturated fatty acid.

Table 3. Changes in body weight, food intake, liver and adipose tissue weight in rats fed different experimental diets for 4 weeks.

\begin{tabular}{cccc}
\hline Group & Control & $5 \%$ FOFB & $10 \%$ FOFB \\
\hline Initial body weight (g) & $176.13 \pm 4.59$ & $176.15 \pm 4.21$ & $176.14 \pm 4.29$ \\
Final body weight (g) & $222.15 \pm 19.48$ & $219.40 \pm 9.34$ & $221.00 \pm 6.88$ \\
Food intake (g/day) & $16.96 \pm 2.13$ & $17.26 \pm 1.98$ & $17.32 \pm 2.15$ \\
Heart weight (g) & $4.721 \pm 0.66$ & $4.78 \pm 0.69$ & $4.76 \pm 0.78$ \\
Relative heart weight & $2.12 \pm 0.71$ & $2.18 \pm 0.91$ & $2.15 \pm 0.79$ \\
Liver weight (g) & $7.06 \pm 0.52$ & $7.08 \pm 1.23$ & $7.04 \pm 0.91$ \\
Relative liver weight & $3.73 \pm 0.13$ & $3.70 \pm 0.26$ & $3.68 \pm 0.49$ \\
Epididymal fat pad & $3.38 \pm 0.20$ & $2.98 \pm 0.96^{*}$ & $2.97 \pm 0.34^{*}$ \\
Abdominal adipose tissue & $0.72 \pm 0.28$ & $0.63 \pm 0.14$ & $0.59 \pm 0.15^{*}$ \\
Adipose tissue weight (g) & $4.10 \pm 0.41$ & $3.61 \pm 0.42$ & $3.56 \pm 0.51^{*}$ \\
Relative adipose weight & $2.17 \pm 0.37$ & $1.92 \pm 0.24$ & $1.89 \pm 0.39^{*}$ \\
\hline
\end{tabular}

Each value is expressed as mean \pm S.D. for ten rats per dietary group. Values in the same row with asterisk are significantly different. ${ }^{*}$ vs. control group $\mathrm{P}<0.05$. 
This result is in line with previous reports. Diet-induced obesity was related with renal lipid accumulation in mice [14]. Consumption of PUFA diet could increase lipoprotein lipase activity and inhibited body fat accumulation in rats [15]. According to another report, there is no correlation between the type of diet fat and the volume of adipose tissue, whereas the amount of dietary fat and the age of an organism are the factors affecting the volume of adipose tissue [16]. In our study, no difference was found in the amount of the food consumption among groups, but the FOFB groups presented lower adipose tissue levels than the control group upon the completion experiment. PUFA decreases the oxidative stress in plasma and regulates the liver and adipose tissue gene expression such as UCP1 mRNA and SCD1 mRNA, which can delay free fatty acids from entering adipose tissue to form triancyglycerol through esterification, and in turn slow down white body fat accumulation [7] [17] [18]. Furthermore, FOFB with major component 8,11-Octadecadienic acid is a powerful natural antioxidant and is able to suppress LPS induced NO production in RAW264.7 macrophages [12]. Excessive free radical and NO production are reported to be associated with various diseases such as obesity [19].

\subsection{Effects of Different Doses of FOFB Diets on Plasma Lipids}

To evaluate the effects of FOFB on the regulation of plasma lipids in rats, the total cholesterol, triacylglycerol, HDL-cholesterol and LDL-cholesterol were measured. Our data showed (Table 4) that the plasma LDL-cholesterol levels were significantly $(\mathrm{P}<0.05)$ decreased in both $5 \%$ and $10 \%$ FOFB groups respectively. The plasam levels of the total cholesterol, triacylglycerol and LDL-cholesterol were significantly $(\mathrm{P}<0.05)$ decreased in the both groups fed with FOFB, respectively. It has been noticed that the effect of FOFB on reduction level of the LDL-cholesterol was dose-dependent, but on the total cholesterol level was not. This could be explained by the fact that either $5 \%$ or $10 \%$ FOFB diet had no effect on the HDL-cholesterol (Table 4). The effect of FOFB on the plasma triacylglycerol level was not dose-dependent either. This phenomenon could be caused by the effect of MUFA which was contained in the diets. It has been proposed that a large amount of dietary MUFA may raise some fractions of plasma lipids [20].

Both of the FOFB groups presented lower level of liver cholesterol (Table 5) as well as the plasma LDLcholesterol. A related study has pointed out that phytosterols can reduce plasma LDL-C [21]. FOFB contains phytosterol such as fucosterol. Higher fucosterol concentration in the liver will result in an increase in the antioxidant enzymes such as hepatic cytosolic superoxide dismutase (SOD), catalase and glutathione peroxidase (GSH-px) activities [22], and inhibit the absorption of chelosterol. The small amount of fucosterol contains in FOFB, which sometimes might be one of the causes of an apparent decrease of hepatic cholesterol in rats.

In conclusion, FOFB contained a large amount of PUFA about 32\% to 35\% [9] [11], which had the effect on reducing plasma lipids and adipose. Our future work will investigate the mechanisms underlying the activities of

Table 4. Changes in plasma lipids and lipoprotein cholesterol in rats fed with different types of diets for 4 weeks.

\begin{tabular}{cccc} 
Group & Control & $5 \%$ FOFB & $10 \%$ FOFB \\
\hline Total cholesterol $(\mathrm{mg} / \mathrm{dl})$ & $326.16 \pm 58.78$ & $287.59 \pm 77.60^{*}$ & $42.51 \pm 9.18^{*}$ \\
Triacylglycerol $(\mathrm{mg} / \mathrm{dl})$ & $49.37 \pm 8.53$ & $16.00 \pm 2.67$ & $43.24 \pm 10.70^{*}$ \\
HDL-cholesterol $(\mathrm{mg} / \mathrm{dl})$ & $16.38 \pm 2.50$ & $7.76 \pm 1.99^{*}$ & $16.51 \pm 2.23$ \\
LDL-cholesterol $(\mathrm{mg} / \mathrm{dl})$ & $8.83 \pm 1.318$ & $7.59 \pm 2.32^{*}$ & \\
\hline
\end{tabular}

Each value is expressed as mean \pm S.D. for ten rats per dietary group. Values in the same row with asterisk are significantly different. ${ }^{*} v s_{\text {control }}$ group $\mathrm{P}<0.05$.

Table 5. Changes in liver lipid in rats fed with different types of diets for 4 weeks.

\begin{tabular}{cccc}
\hline Group & Control & 5\% FOFB & $10 \%$ FOFB \\
\hline Cholesterol & & & \\
$(\mathrm{mg} /$ liver $)$ & $756.23 \pm 67.20$ & $669.19 \pm 88.11^{*}$ & $613.88 \pm 51.61^{*}$ \\
$(\mathrm{mg} / \mathrm{g}$ liver $)$ & $107.24 \pm 7.53$ & $94.50 \pm 8.44^{*}$ & $87.28 \pm 10.70^{*}$ \\
\hline
\end{tabular}

Each value is expressed as mean \pm S.D. for ten rats per dietary group. Values in the same row with asterisk are significantly different. ${ }^{*} v{ }$ control group $\mathrm{P}<0.05$. 
each component of FOFB to provide data for development of an antihyperlipidemic agent.

\section{Acknowledgements}

This work was supported by the Quanzhou Science \& Technology Fund (2007Z12).

\section{References}

[1] Pharmacopoeia Commission of People's Republic of China (2010) Pharmacopoeia of People's Republic of China. Chinese Medical Science \& Technology Press, Beijing, 315.

[2] Matsuda, H., Cai, H., Kubo, M., Tosa, H. and Iinuma, M. (1995) Study on Anti-Cataract Drugs from Natural Sources. II. Effects of Buddlejae Flos on in Vitro Aldose Reductase Activity. Biological \& Pharmaceutical Bulletin, 18, 463466. http://dx.doi.org/10.1248/bpb.18.463

[3] Li, Z.M., Chen, J.J. and Yan, M.H. (2010) Studies on Chemical Constituents of Cortex of Broussonetia papyrifera. Journal of Anhui Agriculture Science, 38, 7288-7290.

[4] Pang, S.Q., Wang, G.Q., Huang, B.K., et al. (2007) Cytotoxic Activities of Total Alkaloids Isolated from Fructus Broussonetia in Vitro. Journal of Chinese Medicinal Materials, 30, 826-828.

[5] Guo, M.X., Wang, M.L., Deng, H., et al. (2013) A Novel Anticancer Agent Broussoflavonol B Downregulates Estrogen Receptor (ER)- $\alpha 36$ Expression and Inhibits Growth of ER-Negative Breast Cancer MDA-MB-231 Cells. European Journal of Pharmacology, 714, 56-64. http://dx.doi.org/10.1016/j.ejphar.2013.05.047

[6] Pang, S.Q., Wang, G.Q., Qin, L.P., Huang, B.K. and Zhang, Q.Y. (2006) Antioxidation Activities of Fructus Broussonetia Haematochrome in Vitro. Journal of Chinese Medicinal Materials, 29, 262-265.

[7] Matsuo, T., Takeuchi, H., Suzuki, H., Suzuki, H. and Suzuki, M. (2002) Body Fat Accumulation Is Greater in Rats Fed a Beef Tallow Diet than in Rats Fed a Safflower or Soybean Oil Diet. Asia Pacific Journal of Clinical Nutrition, 11, 302-308. http://dx.doi.org/10.1046/j.1440-6047.2002.00299.x

[8] Li, Y.H., Hu, L. and Wu, Z.Z. (2011) Fructus Broussonetae Extract Improves Cognitive Function and Endoplasmic Reticulum Stress in Alzheimer's Disease Models. Neural Regeneration Research, 6, 2325-2331.

[9] Huang, B.K., Qin, L.P., Zheng, H.C., et al. (2003) Analysis of Amino Acid and Fatty Acid of Fructus Broussonetiae. Acadamic Journal of Second Military Medical University, 24, 213-213,217,227.

[10] Fukuda, H., Iritani, N., Sugimoto, T. and Ikeda, H. (1999) Transcriptional Regulation of Fatty Acid Synthase Gene by Insulin/Glucose, Polyunsaturated Fatty Acid and Leptin in Hepatocytes and Adipocytes in Normal and Genetically Obese Rats. European Journal of Biochemistry, 260, 505-511. http://dx.doi.org/10.1046/j.1432-1327.1999.00183.X

[11] Yuan, X. and Yuan, P. (2005) Studies on the Effects of Oil and Flavanoids from Fructus Broussonetiae's Antioxidation and Elimination of Free Radicals. Natural of Product Research Developing, 17, 23-26.

[12] Zhao, H., Huang, L., Qin, L., et al. (2011) Antioxidative and Anti-Inflammatory Properties of Chushizi Oil from Fructus Broussonetiae. Journal of Medicinal Plants Research, 5, 6407-6412.

[13] Folch, J., Less, M. and Sloane, G.H. (1957) A Simple Method for the Isolation and Purification of Total Lipids from Animal Tissue. Journal of Biological Chemistry, 226, 497-509.

[14] Jiang, T., Wang, Z.W., Proctor, G., et al. (2005) Diet-Induced Obesity in C57BL/6J Mice Causes Increased Renal Lipid Accumulation and Glomerulosclerosis via a Sterol Regulatory Element-Binding Protein-1c-Dependent Pathway. Journal of Biological Chemistry, 280, 32317-32325. http://dx.doi.org/10.1074/jbc.M500801200

[15] Shimomura, Y., Tamura, T. and Suzuki, M. (1990) Less Body Fat Accumulation in Rats Fed a Safflower Oil Diet than in Rats Fed a Beef Tallow Diet. Journal of Nutrition, 120, 1291-1296.

[16] Edwards, M.S., Smith, B.A., Kainer, R.A., et al. (1993) Effect of Dietary Fat and Aging on Adipose Tissue Cellularity in Mice Differing in Genetic Predisposition to Obesity. Growth Development of Aging, 57, 45-51.

[17] Jones, B.H., Maher, M.A., Banz, W.J., et al. (1996) Adipose Tissue Stearoyl-CoA Desaturase mRNA Is Increased by Obesity and Decreased by Polyunsaturated Fatty Acids. American Journal of Physiology, 271, E44-E49.

[18] Sessler, A.M. and Ntambi, J.M. (1998) Polyunsaturated Fatty Acid Regulation of Gene Expression. The Journal of Nutrition, 128, 923-926.

[19] Luo, R. and Qu, S.Y. (2004) Obesity and Free Radicals. Section of Endocrinology Foreign Medical Sciences, 24, 9-10.

[20] Chang, N.W. and Huang, P.C. (1990) Effects of Dietary Monounsaturated Fatty Acids on Plasma Lipids in Humans. Journal of Lipid Research, 3, 2141-2147.

[21] Nigon, F., Serfaty-Lacrosnière, C., Beucler, I., et al. (2001) Plant Sterol-Enriched Margarine Lowers Plasma LDL in 
Hyperlipidemic Subjects with Low Cholesterol Intake: Effect of Fibrate Treatment. Clinical Chemistry and Laborotary Medicine, 39, 634-640. http://dx.doi.org/10.1515/cclm.2001.103

[22] Lee, S., Lee, Y.S., Jung, S.H., Kang, S.S. and Shin, K.H. (2003) Anti-Oxidant Activities of Fucosterol from the Marine Algae Pelvetia siliquosa. Archives of Pharmacal Research, 26, 719-722. http://dx.doi.org/10.1007/BF02976680 